\title{
Role of C-Reactive Protein in Deciding Duration of Antibiotic Therapy in Neonatal Septicemia
}

\begin{abstract}
Love Kumar Sah, ${ }^{1}$ Prince Pareek ${ }^{2}$, Atanu Pan, ${ }^{3}$ Sameera Thapa, ${ }^{4}$ Reema Garegrat ${ }^{5}$
'Department of Pediatrics, Janaki Medical College, Janakpur, Nepal, 2Department of Neonatology, Bharati Vidyapeeth Deemed to be University, Pune-satara road, Pune, Maharashtra, India, ${ }^{3}$ Department of Pediatrics, College of Medical Sciences, Bharatpur, Nepal, Department of Pediatrics, Dhulikhel Hospital, Dhulikhel, Nepal, ${ }^{5}$ Department of Neonatology, Bharati Vidyapeeth Deemed to be University, pune-satara road, pune -411043, Maharashtra, India.
\end{abstract}

\section{ABSTRACT}

\section{Introduction}

Neonatal septicemia is one of the commonest causes of neonatal morbidity and mortality worldwide. C-Reactive Protein (CRP) is an acute phase reactant that can be expected to fall quickly after efficient elimination of microbial stimulus due to its short half-life. CRP levels may sufficiently reflect the balance between microbes and immune system of the neonate for monitoring the effect of antibiotic treatment and for guiding the duration of antibiotic therapy.

\section{Methods}

A prospective study conducted in ninety neonates admitted with suspected neonatal sepsis during one year in tertiary care hospital in the department of pediatrics, College of Medical Sciences, Bharatpur, Nepal from October 2015 to September 2016. CRP was estimated within 24-72 hours of admission. Then neonates were assigned to one of 3 groups according to CRP levels. Infection unlikely group, infection likely group with two subgroups- CRP guided therapy and 7 days antibiotic therapy.

\section{Results}

Out of 90 cases of suspected neonatal septicaemia antibiotics were stopped in $\leq 7$ days in 61 cases (67.8\%). In 25 out of 30 cases $(27.8 \%)$ of neonatal septicaemia, antibiotics were stopped after 72 hours of initiation. In group II, antibiotics could be stopped in five days in 4 cases and remaining 26 cases antibiotics were given for 7 days. In group III, antibiotics could be stopped in 7 days in one case and remaining 29 cases antibiotics were given more than 7 days.

\section{Conclusions}

CRP has a high negative predictive value $96-100 \%$ and can be used as a marker of neonatal sepsis to reduce duration of antibiotics.

Keywords: C-reactive protein; neonates; antibiotics; septicemia.

Correspondance: Dr. Love Kumar Sah, Department of Paediatrics, Janaki Medical College, Janakpur, Nepal. Email: lovesah83@gmail.com, Phone: +977-9854027559. 


\section{INTRODUCTION}

Neonatal septicaemia is one of the commonest causes of neonatal morbidity and mortality worldwide. The incidence varies from 1-4/1000 live births in developed countries, to $10-50 / 1000$ live birth in developing countries.(1,2) In Nepal, in the year 2006, among the 25000 estimated neonatal deaths $46 \%$ were due to neonatal infection.(3)

Neonatal septicaemia is defined as a clinical syndrome characterized by signs and symptoms of infection with or without accompanying bacteraemia in the first month of life.(4) It encompasses various systemic infections of the newborn such as septicaemia, meningitis, pneumonia, arthritis, osteomyelitis, and urinary tract infections.

Its clinical manifestations vary from being subtle to specific, testing the very skill of a paediatrician. The inability to be certain of an infection coupled with nonspecific signs of life threatening illness in neonates resulted in widespread use of antibiotics aggravating the problem of antibiotic resistance. There is an increasing need for careful evaluation of indications and duration of treatment, which in turn would shorten the length and cost of hospital stay and diminish the side effects of antibiotics.

Over the last decades, a variety of laboratory tests have been developed to enhance the early and accurate identification and treatment of infants with sepsis. Various tests include Micro-ESR, Band neutrophil ratio (B/N ratio), Procalcitonin, Interleukin (IL)-6, IL-8, Tumor necrosis factor (TNF)- $\alpha$, and C-reactive protein (CRP).

Serum CRP, an acute phase reactants, is synthesized in the liver within 6-8 hours in response to inflammatory cytokines and may raise 1000 folds during an acute phase response.

(5) CRP level can be expected to fall quickly after efficient elimination of microbial stimulus due to its short half-life of 19 hours.(6) Thus, CRP levels may sufficiently reflect the individual balance between the microbes and the immune system of the neonate for monitoring the effect of antibiotic treatment and for guiding the duration of antibiotic therapy. $(7,8)$

Evidence exists to support the use of serial CRP measurements to establish or exclude the diagnosis of sepsis in full term or near term infants. So this proposed prospective study was undertaken to determine whether CRP can be used as a parameter to identify the time period when antibiotic therapy can safely be discontinued in suspected neonatal septicaemia admitted in College of Medical Sciences, Bharatpur, Nepal.

\section{METHODS}

\section{Study Population}

A prospective study was conducted in neonates admitted with suspected neonatal sepsis during one year in tertiary care hospital in the department of pediatrics, College of Medical Sciences, Bharatpur, Nepal from October 2015 to September 2016. All neonates with birth weight more than 1500 gms and received antibiotic therapy for suspected neonatal sepsis as per signs and symptoms were included in the study. Neonates who had undergone mechanical ventilation or had central lines in situ because of high risk of re-infection; neonates who had undergone surgical operation because of risk of wound infection; neonates with diagnosis of meningitis as they require longer duration of treatment with antibiotics; neonates who had exchange transfusion; neonates with metabolic aberrations; neonates with chromosomal abnormalities because persistent clinical and hematologic abnormalities frequently prompt repeated courses of antibiotic therapy; neonates who 
had received parenteral antibiotic therapy before admission and newborn who had been resuscitated before admission were excluded. Informed consent was taken from the parents of enrolled neonates and the study was approved by the ethical committee of COMS-TH.

\section{Clinical and laboratory investigations}

All cases were thoroughly evaluated by history and physical examination with investigations and findings was recorded in a predesigned proforma. Neonatal septicaemia was suspected with "sepsis score" which include following signs and symptoms such as refusal for feed, abdominal distention, vomiting, lethargy, jaundice, poor cry, seizures, diarrhoea, apnea, tachypnea, poor capillary refill, hypothermia, fever and umbilical discharge.

In absence of clinical features the newborn having risk factors (one major or two minor) was taken as suspected septic cases.

Major risk factors: Rupture of membrane more than 18 hrs, chorioamniontis, maternal intrapartum fever more than $38^{\circ} \mathrm{C}$.

Minor risk factors: Rupture of membrane more than 12 hours, maternal WBC count more than 15000/cu mm, preterm labour, low birth weight, foul lochia, maternal colonization.

All neonates underwent sepsis screen as per standard protocol of the department which includes:

- Total leukocyte count (TLC) and differential leukocyte count (DLC): Abnormal WBC (total $>30000$ or $<5000$ / cumm or absolute neutrophil count $<1500$ /cumm) was considered positive for septicaemia.

- $\quad$ Band cells count more than $20 \%$ or a band count to total neutrophil count ratio of more than 0.2 or presence of any of the abnormal neutrophil was considered positive for sepsis.

- Chest X-ray

- Blood culture: Conventional blood culture method was done.

In all neonates the blood sample was collected from peripheral vein with all aseptic precautions, prior to administration of any antibiotic therapy. $1 \mathrm{ml}$ of blood was collected in $5 \mathrm{ml}$ of brain heart infusion broth and immediately transported to thelaboratory. Investigations such as X-ray abdomen, ultrasound cranium, CT scan brain, CSF examination, liver function tests, renal function tests, umbilical swab culture and sensitivity, vaginal swab of mother for culture and sensitivity, stool examination for occult blood and microscopy, urine routine microscopy and culture sensitivity, serum electrolytes, hemoglobin, platelet count, prothrombin time and activated partial thromboplastin time and blood group was done as required.

CRP was detected by latex agglutination slide test from serum sample by HumaTex CRP kit. The presence of agglutination indicates a CRP concentration equal or greater than $6 \mathrm{mg} / \mathrm{l}$ and considered positive for sepsis.

After admission blood was drawn for culture and sensitivity and other relevant investigations was sent and broad spectrum antibiotics covering both gram positive and gram negative organisms was started. (Injection Cefotaxime and Amikacin)

CRP was estimated within 24-72 hours of admission. Then neonates were assigned to one of the 3 study groups according to their CRP serum levels. 


\section{Study groups}

\section{Infection unlikely}

\section{Group 1:}

This group included infants with CRP levels less than $6 \mathrm{mg} / \mathrm{l}$ at $24-72 \mathrm{hours}$ after the initiation of antibiotic therapy. Antibiotics were discontinued irrespective of other laboratory or clinical indices of infection unless decided by the attending consultant.

\section{Infection likely}

If CRP was elevated more than $6 \mathrm{mg} / \mathrm{l}$ after 24-72 hours of first dose of antibiotic, group was divided into two sub groups.

\section{Group 2: CRP guided therapy}

In this sub group, CRP was estimated on alternate day and as soon as CRP level was less than $6 \mathrm{mg} / \mathrm{l}$ antibiotics were stopped.

\section{Group 3: 7 day therapy}

In this sub group, antibiotics once started were continued for 7 days and CRP was estimated on seventh day. If CRP was less than $6 \mathrm{mg} / \mathrm{l}$ and neonate was asymptomatic, antibiotics were stopped unless decided differently by the attending consultant.

\section{Follow-up}

Neonates were kept up to 48 hours after stopping the antibiotics to observe for recurrence of clinical feature of septicemia. The study group was divided into two groups.

No relapse- If no occurrence of symptoms of septicemia within four weeks of discharge or the baby required antibiotics for different diagnosis other than septicemia.

Relapse-If the baby needed another course of antibiotics for suspected/ proved septicemia within four weeks after discharge.

\section{Sample for blood culture}

Under aseptic technique, $1 \mathrm{ml}$ blood was withdrawn and transferred to culture media bottle containing $5 \mathrm{ml}$ of brain heart infusion broth (BHI) and sent to laboratory for further processing.

\section{CRP estimation}

1-2 cc of venous blood was drawn and serum was separated for testing. One drop of serum was taken by dropper provided in HumaTex CRP kit which was serially diluted with normal saline (1: 2, 1: 4, 1: 8, 1: 16, 1:32, 1: 64, $1: 128)$, as per the instructions in the manual supplied by the manufacturers. (Human Diagnostic). All the CRP reagents, which were stored at 2 to $8^{\circ} \mathrm{C}$ was brought to room temperature before use. After shaking the $\mathrm{CRP}$ reagent gently, one drop of CRP reagent was mixed with serially diluted serum for two minutes by rotating the slides manually. The macroscopic clumping was observed as positive reaction. Quality control was observed after regular intervals with positive control and negative control serum.

Results were interpreted by multiplying the highest dilution of positive result by $6 \mathrm{mg} / \mathrm{l}=$ $6 \mathrm{X}$ dilution value. $6 \mathrm{mg} / \mathrm{l}$ was normal value in this study.

Example: Titre 1:16

CRP concentration $=16 \times 6[\mathrm{mg} / \mathrm{l}]=[96 \mathrm{mg} / \mathrm{l}]$.

\section{Statistical methods:}

Statistical analysis was done with Statistical Package for Social Sciences (SPSS) version 20.0. Chi Square and Negative predictive value were applied whenever statistical analysis was necessary. Help of the statistician from the department of community medicine, College of Medical Sciences was taken as and when required. 


\section{RESULTS}

\section{Patient characteristics}

Ninety cases of neonatal septicaemia were studied over a period of one year. $73.3 \%$ of cases presented within 72 hours of life, remaining $26.7 \%$ of cases presented after 72 hours of life. Among these 14 cases presented between 4-7 days, 7 cases presented between 8-14 days and 3 cases between 15-28 days. More than half $55.6 \%$ were male and $44.4 \%$ were female, which were equally distributed among 3 groups.

Approximately one third of cases (28) weighed between $2.6-3 \mathrm{~kg}$ and more than $3 \mathrm{~kg}$ in each group. Remaining one third of cases weighed between $1.5-2 \mathrm{~kg}$ and $2.1-2.5 \mathrm{~kg}$. Majority $(74.4 \%)$ of patients were of term gestation, followed by preterm (22.2\%) and post term (3.3\%). Equal number of patients had risk factor of maternal fever (41.1\%) and PROM>18 hrs $(41.1 \%)$. Majority of patients presented with complaints of poor feeding $(68.9 \%)$, tachypnea $(65.6 \%)$, poor cry $(48.9 \%)$ followed by fever (32.2\%), Lethargy (26.7\%), conjunctivitis $(25.6 \%)$ and excessive cry $(17.8 \%)$. Only 16 (18\%) cases were blood culture positive.

Most of blood culture results were positive in Group III (30\%) and Group II (23.3\%) while none of cases were blood culture positive in Group I. Among culture positive 16 cases, 10 cases (62.5\%) culture grew gram negative organisms and in 6 cases $(37.5 \%)$ culture showed gram positive organism. Among gram negative organisms E coli (25\%) was the commonest organism isolated followed by Pseudomonas aeruginosa (18.75\%) and Klebsiella pneumonia (12.5\%).CONS (18.75\%) and Staphylococcus aureus (18.75\%) were the commonest among gram positive organisms.

\section{CRP guided distribution of cases}

\begin{tabular}{|c|c|c|c|c|c|c|}
\hline \multicolumn{7}{|c|}{$\begin{array}{l}\text { Table 1. CRP guided distribution of treatment, relapse } \\
\text { rate in various groups and correlation with blood culture } \\
\text { results. }\end{array}$} \\
\hline $\begin{array}{l}\text { CRP } \\
\text { value }\end{array}$ & $\begin{array}{l}\text { Groups } \\
\text { (Case) }\end{array}$ & $\begin{array}{l}\text { Duration } \\
\text { of } \\
\text { therapy }\end{array}$ & $\begin{array}{l}\text { No } \\
\text { of } \\
\text { case }\end{array}$ & $\begin{array}{l}\text { Blood } \\
\text { culture } \\
\text { positive } \\
\text { cases }\end{array}$ & $\begin{array}{l}\text { Re- } \\
\text { lapse }\end{array}$ & $\begin{array}{l}\text { Negative } \\
\text { Predictive } \\
\text { value (\%) }\end{array}$ \\
\hline \multirow{2}{*}{$<6 \mathrm{mg} \%$} & \multirow{2}{*}{$\begin{array}{l}\text { Group } \\
\text { I(30) }\end{array}$} & 3 days & 25 & Nil & 5 & 80 \\
\hline & & 7 days & 5 & $\mathrm{Nil}$ & Nil & 100 \\
\hline \multirow{4}{*}{$>6 \mathrm{mg} \%$} & \multirow{2}{*}{$\begin{array}{l}\text { Group } \\
\text { II(30) }\end{array}$} & 5 days & 4 & Nil & Nil & 100 \\
\hline & & 7 days & 26 & 7 & 1 & 96 \\
\hline & \multirow{2}{*}{$\begin{array}{l}\text { Group } \\
\text { III(30) }\end{array}$} & 7 days & 1 & Nil & Nil & 100 \\
\hline & & $>7$ days & 29 & 9 & 1 & 96 \\
\hline
\end{tabular}

Group I: In 30 cases out of 90 cases of suspected neonatal septicaemia, CRP was negative after 72 hours and antibiotics were stopped. All blood cultures showed no growth. However there were five cases of relapse in the following four weeks.

Group II: This group comprised of 30 cases out of which CRP returned to normal in four cases on 5th day and antibiotics were stopped. Blood culture was negative and there was no relapse. In rest of 26 patients antibiotics were continued beyond 7 days as CRP was raised. Blood culture was positive in 7 cases though there was only one relapse.

Group III: This group also comprised of 30 cases out of which CRP become negative on 7th day of treatment in one case and antibiotics were stopped and had no relapse. In rest of 29 cases, antibiotics were continued beyond 7 days as CRP was raised on 7 th day of treatment. Blood culture was positive in 9 cases though there was one relapse. 


\section{CRP guided duration of treatment}

\begin{tabular}{|l|c|c|c|c|c|}
\hline \multicolumn{5}{|c|}{ Table 2. CRP guided overall durations of treatment. } \\
\hline \multirow{3}{*}{ Group } & \multicolumn{4}{|c|}{ Duration of treatment } & \multirow{2}{*}{ Total } \\
\cline { 2 - 5 } & \multicolumn{3}{|c|}{$\leq 7$ days days } & \\
\cline { 2 - 6 } & 3 days & 5 days & 7 days & & 30 \\
\hline Group I & 25 & & 5 & - & 30 \\
\hline Group II & - & 4 & 26 & - & 30 \\
\hline Group III & - & - & 1 & 29 & 90 \\
\hline \multirow{2}{*}{ Total } & 25 & $4(4.4 \%)$ & 32 & 29 & $(35.6 \%)$ \\
\hline
\end{tabular}

Out of 90 cases of suspected neonatal septicaemia antibiotics were stopped in $\leq 7$ days in 61 cases $(67.8 \%)$. In 25 out of 30 cases $(27.8 \%)$ of neonatal septicaemia, antibiotics were stopped after 72 hours of initiation of antibiotics. Five cases were given antibiotics for 7 days as decided by attending consultant despite negative CRP. In group II out of 30 cases antibiotics could be stopped in five days in 4 cases and remaining 26 cases antibiotics were given for 7 days as CRP was raised. In group III out of 30 cases antibiotics could be stopped in 7 days in one case and remaining 29 cases antibiotics were given more than 7 days.

\section{Discussion}

Neonatal sepsis is one of the leading cause of neonatal deaths.(9) The diagnosis of infection during the neonatal period can be difficult. The golden way to prove the presence of infection is to isolate the organism. Treatment cannot be delayed as the outcome directly depends on the early and adequate antimicrobial therapy.

The present study evaluated the role of CRP in deciding the duration of antibiotic therapy in suspected neonatal bacterial infection and to determine whether CRP can be used as a parameter to identity the time point at which antibiotics can be safely discontinued in suspected bacterial infection. Incidence of EOS was $73.3 \%$ and LOS was $26.7 \%$ in present study.
So EOS was more common than LOS which is in concordance with the study of Gupta et al. (1993)(10) . This study found $76.4 \%$ and $23.6 \%$ of EOS and LOS respectively.

Vesikari et al. (1985)(11) also reported early onset in most of the patients with neonatal sepsis. Similarly Khatua et al. (1986)(12) observed that $70 \%$ cases developed early onset septicaemia. The higher incidence was probably due to inclusion of maternal risk factors like prolonged rupture of membranes, $\mathrm{H} / \mathrm{o}$ maternal fever $>101.4 \mathrm{~F}$.

In the present study majority of cases $74.4 \%$ were of term gestation and $22.2 \%$ cases were of preterm gestation. So term babies are more affected than preterm babies in neonatal septicaemia which is inconsistent with other studies.(13,14,15).

In the present study poor feeding, tachypnea, poor cry was the commonest symptom followed by fever and lethargy. Khinchi et al. (2010) (15) observed the similar results, poor feeding, tachypnea and fever was the commonest symptom followed by poor cry, fever and jaundice.

The incidence of positive blood culture in the present study is $18 \%$ which is in concordance with the studies conducted by Shrestha et al. (2007) (16) and Jain et al. (2003)(14). The incidence was $20 \%$ and $28.3 \%$ respectively. Another study done by Shaw et al. (2007)(17) showed significantly higher incidence $(44.9 \%)$ of positive blood culture. The incidence was higher probably due to inclusion of all term and preterm neonates in the study. The incidence of gram negative organism is $62.5 \%$ and gram positive organism is $37.5 \%$. Several studies found much higher incidence of gram negative organism(14,18,19). The prevalence of $\mathrm{E}$ coli in the present study was consistent with studies done by Jain et al. (2003) (14). However another study done by Shaw et al. (2007)(17) isolated Staphylococcus aureus and Klebseilla pneumonia as the most common organism. 


\section{Comparison of CRP guided therapy groups}

Group I- In the present study, antibiotics were discontinued in $28 \%$ of neonates after 3 days treatment and there were relapse in five cases over the next 4 weeks. Similar results have been claimed by Ehl et al. (1997)(20) in which antibiotics were discontinued in $47.7 \%$ and Jaswal et al. (2003)(5) in which antibiotics were stopped in $44 \%$ of cases presented within 3 days after starting treatment. The authors have reported the negative predictive value of CRP guided therapy to be $99 \%$ and $100 \%$ which is higher with the figure $80 \%$ in the present study.

In another study conducted by Philip et al. (2000)(21) antibiotics were stopped in 162 cases out of 425 (38\%) within 48 hours based on CRP value. No relapse was reported in the study with negative predictive value of $100 \%$ which is higher to the present study. Relapse cases are more in this group in present study in comparison to other study. It is probably because Serum CRP determined in other study was done by nephelometer which is more accurate than traditional latex agglutination slide test used in present study.

Group II- In this group 4 case out of 30, antibiotics could be stopped on 5 th day whereas in 26 cases CRP levels were still raised even on 7 th day. Since there was one relapse in this group negative predictive value is $96 \%$ which is comparable to the study conducted by Ehl et al. (1997)(20) which reported 38 out of 39 cases $(97.8 \%)$, guided by CRP within 6 days respectively with a negative predictive value of $99 \%$. However there were four cases in this group in which antibiotics were stopped on 5th day to be of some statistical significance.

Group III- In this group antibiotic could be stopped on 7 th day in 1 out of 30 cases assigned to this group with a negative predictive value of $100 \%$. In 29 cases treatment was continued beyond 7 days as CRP levels were still raised. Since there was one relapse in this group, negative predictive value is $96 \%$ which is comparable with
Ehl et al. (1997)(20). In their study serum CRP continued to be raised in $6 \%$ of patients after 5 th day of therapy. Two out of 42 patients had likely relapse and needed second course of antibiotics within 4 weeks giving negative predictive value of $95 \%$. Hundred percent negative predictive value of CRP reported by Philip et al. (2000)(21) is comparable than the present study. Similarly negative predictive value of CRP was $100 \%$ in study done by Jaswal et al. (2003)(5) which is higher than present study. Antibiotics were stopped within 7 days in one out of 30 cases in this study.

This study has various limitations like (i) the results are only valid for the specified subgroup of non-intubated neonates of $>1500 \mathrm{gm}$ without central catheters who were treated within first week of life. (ii) These results are based on specific combination of antibiotics used in the study and specific pathogens prevalent at this institution. Therefore, extrapolation of this data to other institutions should be done with great care. (iii) The relapse rates in the CRP-guided therapy (group II) and 7 day therapy (group III) are preliminary, owing to the small sample size of the study. However, this represents an important basis for a multicenter trial. (iv) The incidence of positive blood cultures in this study was relatively low, mostly because neonates with very low birth weights and invasive material were excluded.

\section{CONCLUSIONS}

Negative predictive value of serial serum CRP is $96-100 \%$ in deciding the duration of antibiotic therapy in neonatal septicemia upto 7 days. Duration of antibiotic therapy could be reduced to $<7$ days in $67.8 \%$ cases and 72 hours in $28 \%$ cases in the present study. This has implication in reducing the cost of therapy, duration of hospitalization and preventing over use of antibiotics. Newborn with suspected septicemia having raised serum CRP levels and positive blood culture need longer duration of antibiotic therapy ( $>7$ days). 


\section{REFERENCES}

1. Kliegman RM, Behrman RE, Jenson HB. The fetus and the neonatal infant. In: Stoll BJ, Kleigman RM, editors. Nelson textbook of pediatrics. 17th ed. Philadelphia: WB Saunders CO; 2004. p. 623-39.

2. Forfar JO, Arneil GC, McIntosh N, Helms P, Smyth R. Neonatal infection. In: Khalid $\mathrm{N}$, editor. Forfar and Arneil textbook of pediatrics. 6th ed. Edinburgh; New York: Churchill Livingstone CO; 2003. p. 336-43.

3. Demographic and Health Survey. Kathmandu: Ministry of Health and Population, New ERA, and Macro International Inc; 2006.

4. Sankar MJ, Agarwal R, Deorari AK, Paul VK. Sepsis in the newborn. Indian J Pediatr 2008;75(3):261-6.

5. Jaswal RS, Kaushal RK, Goel A, Pathania K. Role of C-reactive protein in deciding duration of antibiotic therapy in neonatal septicemia. Indian Pediatr 2003;40(9):880-3.

6. Vigushin DM, Pepys MB, Hawkins PN. Metabolic and scintigraphic studies of radioiodinated human $\mathrm{C}$-reactive protein in health and disease. J Clin Invest 1993;91(4):1351-7.

7. Speer C, Bruns A, Gahr M. Sequential determination of CRP, alpha 1-antitrypsin and haptoglobin in neonatal septicaemia. Acta Paediatr Scand 1983;72(5):679-83.

8. Hindocha P, Campbell CA, Gould JD, Wojciechowski A, Wood CB. Serial study of $C$ reactive protein in neonatal septicaemia. Arch Dis Child 1984;59(5):435-8.

9. National neonatal health strategy. Family health division, Department of health services, Ministry of health, Government of Nepal 2004; 1-4.

10. Gupta P, Murali MV, Faridi MM, Kaul PB, Ramachandran VG, Talwar V. Clinical profile of klebsiella septicemia in neonates. Indian J Pediatr 1993;60(4):565-72.
11. Vesikari T, Janas M, Gronroos P, Tuppurainen $N$, Renlund M, Kero P, et al. Neonatal septicaemia. Arch Dis Child 1985;60(6):542-6.

12. Khatua SP, Das AK, Chatterjee BD, Khatua S, Ghose B, Saha A. Neonatal septicemia. Indian J Pediatr 1986;53(4):509-14.

13. Gessner BD, Castrodale L, Soriano-Gabarro M. Aetiologies and risk factors for neonatal sepsis and pneumonia mortality among Alaskan infants. Epidemiol Infect 2005;133(5):877-81.

14. Jain NK, Jain VM, Maheshwari S. Clinical profile of neonatal sepsis. Kathmandu Univ Med J 2003;1(2):117-20.

15. Khinchi YR, Kumar A, Yadav S. Profile of neonatal sepsis. J Coll Med Sci Nepal 2010;6(2):1-6.

16. Shrestha P, Das BK, Bhatta NK, Jha DK, Das B, Setia A, Tiwari A. Clinical and bacteriological profiles of blood culture positive sepsis in newborn. J Nepal Paediatr Soc 2007;27:64-67.

17. Shaw CK, Shaw P, Thapalial A. Neonatal Sepsis bacterial isolates and antibiotic susceptibility patterns at a NICU in a tertiary care hospital in western Nepal: A retrospective analysis. Kathmandu Univ Med J 2007;5(18):153-60.

18. Guha DK, Jaspal D, Das K, Guha AR, Khatri RL, Kumar RS. Outcome of neonatal septicemia: a clinical and bacteriological profile. Indian Pediatr 1978;15(5):423-7.

19. Kuruvilla KA, Pillai S, Jesudason M, Jana AK. Bacterial profile of sepsis in a neonatal unit in south India. Indian Pediatr 1998;35(9):851-8.

20. Ehl S, Gering B, Bartmann P, Hogel J, Pohlandt F. C-reactive protein is a useful marker for guiding duration of antibiotic therapy in suspected neonatal bacterial infection. Pediatrics 1997; 99(2):216-21.

21. Philip AG, Mills PC. Use of C-reactive protein in minimizing antibiotic exposure: experience with infants initially admitted to a well-baby nursery. Pediatrics 2000;106(1):E4.

Citation: Sah L, Pareek P, Pan A, Thapa S, Garegrat R. Role of C-Reactive Protein in Deciding Duration of Antibiotic Therapy in Neonatal Septicemia. JCMS Nepal. 2020; 16(4):230-37. 